\begin{tabular}{|l|l|}
$\begin{array}{l}\text { Postprint } \\
\text { Version }\end{array}$ & 1.0 \\
\hline Journal website & http://onlinelibrary.wiley.com/doi/10.1111/birt.12185/abstract \\
\hline Pubmed link & http://www.ncbi.nlm.nih.gov/pubmed/26467657 \\
\hline DOI & $10.1111 /$ birt.12185 \\
\hline
\end{tabular}

This is a NIVEL certified Post Print, more info at http://www.nivel.eu

\title{
Women's Suggestions for Improving Midwifery Care in The Netherlands
}

\author{
CARIEN I. BAAS RM, MSC,JAN JAAP H. M. ERWICH MD, PhD, Therese A. Wiegers PhD,T. \\ PAUl DE COCK PhD,EILEEN K. HutTon RM, PHD
}

\begin{abstract}
Background

The experience of the care a woman receives during pregnancy and childbirth has an immediate and long-lasting effect on her well being. The involvement of patients and clients in health care has increased over the last decades. The Dutch maternity care system offers an excellent opportunity to explore and involve women's suggestions for the improvement of midwifery care in the current maternity care model.

Methods

This qualitative study is part of the "DELIVER" study. Clients were recruited from 20 midwifery practices. Purposive sampling was used to select the practices. The clients received up to three questionnaires, in which they could respond to the question; "Do you have any suggestions on how your midwife could improve his/her provision of care?" The answers were analyzed with a qualitative thematic content analysis, using the software program MAXQDA.

Results

Altogether, 3,499 answers were provided. One overarching concept emerged: clients' desire for individualized care. Within this concept, suggestions could be clustered around 1) provider characteristics: interpersonal skills, communication, and competence, and 2) service characteristics: content and quantity of care, guidance and support, continuity of care provider, continuity of care, information, and coordination of care.

Conclusions

Informed by the suggestions of women, care to women and their families could be improved by the following: 1) more continuity of the care provider during the prenatal, natal, and postnatal periods, 2) more information and information specifically tailored for the person, 3) client-centered communication, and 4) a personal approach with 5) enough time spent per client.
\end{abstract}




\section{INTRODUCTION}

The experience with the care received during pregnancy and childbirth has an immediate and long-lasting effect on a woman's well being and her relationship with her child [1].

There are various factors which can affect women's experience with maternity care, including women's characteristics (age, parity, socio-economic status, etc.), factors relating to the childbirth process (complications, length of birth, etc.), the model of maternity care, and aspects within the model of care, including continuity of care and caregiver, patient centeredness, the quality of relationship with the caregiver, type of caregiver, personal treatment (affection and communication aspects), being in control, fulfillment of expectations and preferences, quantity of prenatal visits, use of interventions, pain medication, and information provision [2-21]. Research on the experiences with care can be challenging $[2,4,11,12,20]$. In general, there is a lack of variation in results; typically at least 80 percent of respondents express satisfaction for any given question [21]. Furthermore, clients are often reluctant to criticize caregivers [21]. This reluctance has been explained by patients' gratitude, loyalty, and confidence in the health care system. Nevertheless, when either more specific questions or more open-ended questions are asked, dissatisfaction with care can be solicited $[4,21]$.

The basic assumption, in the Netherland's maternity care model, is that a healthy woman with an uncomplicated pregnancy has no need to see another care provider apart from her midwife. However, when complications occur, or threaten to occur, she will receive secondary care from an obstetrician [20]. This maternity care model is described as a shared care model of care, even though 27.4 percent of all women receive care from a midwife only, during the prenatal, natal, and postnatal period, so their care is entirely midwife led [22]. In addition, there are also women whose care is referred to the obstetrician in the hospital (secondary care) during childbirth, but whose midwife remains present throughout the birth and provides postpartum care. The perinatal mortality rates in the Netherlands were reported as relatively unfavorable compared with other European countries, contributing to a debate about the Dutch health care system [23-26]. In recent years, there has been a lot of discussion between professionals and in the general media about changing the system into a more integrated form of care, with fewer barriers for cooperation between primary and secondary care $[23,26]$. In 2009, the Dutch Minister of Health instructed a steering group (Steering Group Pregnancy and Childbirth), to write a report with recommendations to improve the maternity care organization and reduce perinatal mortality in the Netherlands. In their recent report, one of the recommendations was to put the pregnant woman "in the center of care," which was explained as: professionals should take into account the expectations, desires and fears of the pregnant woman, and her medical and social risks [26]. Therefore it is important to know what women's wishes and expectations are with regard to maternity care.

The involvement of patients and clients in health care has increased over the past few decades, and can be seen by the growing amount of literature about informed and shared decision making and patient involvement (or activation, enablement, engagement, participation, and empowerment) [26-32]. The involvement of clients and patients in their care seems to result in more satisfaction with care and improved health care outcomes $[31,32]$. Additionally, women's expectations and experiences 
of maternity care can influence decisions about the organization and provision of services and therefore are increasingly important to health care professionals, administrators, and health policy makers [2-4].

Little is known about women's perspective on how midwifery care could be improved and we would like to add the voices of women to the discussion about the organization of midwifery care in the Netherlands. At this moment, while changes are not yet institutionalized, the Dutch maternity care system offers an excellent opportunity to explore women's ideas and suggestions about maternity care within the still partly midwife-led care model. For that reason, we used open-ended questions to explore women's suggestions for improving (primary) midwifery care in the Netherlands.

\section{METHODS}

\section{The DELIVER Study}

This study is part of the "DELIVER" study, which was created to investigate the organization, accessibility, and quality of primary midwifery care in the Netherlands. Data from clients and practices were collected during the period from September 2009 to April 2011 [33].

\section{Recruitment}

Clients were recruited from 20 midwifery practices. Purposive sampling was used to select practices, using three stratification criteria, region, level of urbanization, and practice type (dual practice with two midwives or group practice, with $>2$ midwives). The 20 participating practices included 108 midwives and about 8,200 clients per year. A more detailed description of the procedures followed in this study has been reported by Manniën et al [33].

\section{Data Collection "DELIVER" Study}

The primary aim of the "DELIVER" client questionnaires was to develop a profile of a pregnant woman in the Netherlands, her background, her health, her lifestyle, her work, her use of health care in general and to assess her expectations and experiences about midwifery care. Clients received up to three questionnaires depending on their gestational age at inclusion: questionnaire one $(\mathrm{Q} 1=$ early prenatal) was completed before 35 weeks (on average around 20 weeks' gestation), questionnaire two (Q2 = late prenatal) between 35 weeks and birth, and questionnaire three $(\mathrm{Q} 3=$ postpartum) at about 6 weeks postpartum. Each of the three questionnaires consisted of 70-90 questions.

\section{Evaluating Suggestions for Improvement}

At the end of each of the three DELIVER questionnaires, women were asked to respond to the open-ended question: "Do you have any suggestions on how your midwife could improve his/her provision of care?" Their answers to these questions are the focus of this study.

\section{Qualitative Analyses}

To investigate women's suggestions for improving midwifery care in the Netherlands, a qualitative thematic content analysis was performed using the software program MAXQDA (VERBI Software GmbH, Berlin, Germany). The open-ended questions resulted in short constructs of answers, which consisted of not more than 3 lines on average. To make it possible to distinguish the different periods 
in pregnancy and after childbirth, questionnaires from each time period were analyzed separately. The data analysis was inductive. Two reviewers began the analyses by independently repeatedly reading the text segments. Thereafter, a systematic line-by-line analysis was performed to derive codes. One segment of text could contain several codes. One reviewer analyzed the codes and then categorized them according to similarities to form overarching themes. A second reviewer independently coded responses and then compared that categorization with the first reviewer and consensus was reached. The next phase involved reviewing and refining the themes (to create a thematic map). To evaluate whether the thematic map fits the data set, the second reviewer coded around 100 responses with the map. If there was uncertainty, this was discussed between the reviewers until a consensus was reached. In this way, the essence of the content of each theme was identified. Themes are presented along with quotations of comments made by women, followed by age, parity, and questionnaire (Q1-early prenatal, Q2-late prenatal or Q3postpartum) in parentheses.

In keeping with the exploratory purpose of this study, we did not quantify our results. The emergent themes are presented using a qualitative, descriptive approach whereby central themes are illustrated using quotes as a means of developing our understanding of the range of their perspectives and experiences. This study does not evaluate how widespread the voices examined here are.

\section{RESULTS}

\section{Participants}

Altogether we received 3,499 answers to the open-ended questions derived from three questionnaires. These suggestions provide an insight into how midwives could improve their professional care. Figure 1 shows that 22.0 percent of women completed Q1 (early pregnancy) and responded to the open-ended question. In Q2 (late pregnancy) and Q3 (postpartum) the percentage was 33.0 and 24.4, respectively.

\section{[FIGURE 1]}

The group of respondents who completed the open-ended questions was similar to the group who did not complete the open-ended questions on age, parity, and nationality, but not on education level, with more women having a higher education level in the group who responded to the open-ended questions (Table 1).

\section{[TABLE 1.]}

The derived themes and subthemes are given in Table 2. In general, the suggestions were clustered around 1) provider characteristics or 2) service characteristics. The overarching concept of "individualized care" describes the desire of women to have their care adjusted to the individual (and her partner), as opposed to the increasing protocolization of care. The concept of individualized care, which emerged within almost all themes, may include individualized numbers of consultations or home visits, individualized (quantity of) guidance and support, and individualized information provision. Respondents suggested that asking women and partners for their wishes and expectations would be a step toward accomplishing personalized care. Although in qualitative research it is not as much about quantity as about quality, it was interesting to observe that the majority of the comments concerned 
Baas, C.I., Erwich, J., Wiegers, T.A., Cock, T.P. de, Hutton, E.K. Women's suggestions for improving midwifery care in The Netherlands. Birth: Issue in Perinatal Care: 2015, 42(4), 369-378

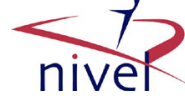

interpersonal skills, a shortage of information, and a lack of continuity of the care provider. In the following text, the midwife will be referred to as "she" although we know that there are men working as midwives as well.

\section{[TABLE 2]}

\section{Provider Characteristics}

Women made suggestions about the midwife as an individual and as a professional. When women made suggestions about the midwife as an individual, most suggestions were about the interaction between the midwife and the women/others, the midwife's communication skills, or about her personality and other characteristics. When women referred to the midwife as a professional, they frequently mentioned the midwife's competence and in particular their interpretation of the midwife's skills.

\section{Interpersonal Skills}

\section{Interaction with Client and Others}

Women indicated that some midwives could be more friendly, respectful, and empathetic toward clients and partners. There was a clear demand to "be taken seriously" with a personal approach instead of a businesslike approach. Women also wanted their midwife to be engaged with them during physical examinations and not to have interactions feel routine.

Keep every check-up "personal." For them it is the next set of parents, but for the parents it is a very important moment that you look forward to, and you don't want to get the feeling that everything is done in a hurry. (30 years, nulli, Q1)

Not so curt, and less businesslike. (40 years, mult, Q1)

Take more time, and show genuine interest before and after childbirth. (31 years, nulli, Q3)

Many women indicated that they wanted the midwife to be more interactive with their partner, children, or others present during care. In the postpartum questionnaire, women referred to the sometimes dismissive interaction between the midwife and the maternity care assistant (maternity care assistants provide care for 8-10 days postpartum (3-6 hours per day). In addition, the midwife visits the new family three to five times during this period [20]).

Think about my husband more, if he is present. He is not being involved sometimes. (23 years, nulli, Q1)

Take the opinion of the maternity care assistant more seriously, during the first week postpartum. She spends more time with the family after all, and she knows the possible problems. (30 years, nulli, Q3)

\section{Communication Skills}

Women indicated that midwives could improve client-centered communication and suggested a number of other things, and midwives could improve their listening skills. Clients also expressed a desire for midwives to show that they take their clients seriously.

Listen more carefully and be interested, sometimes seems to work routinely. (29 years nulli, Q2)

Listen to what someone says; I said that I had complaints with my pubic bone, but she kept insisting it was my stitches. (37 years, mult, Q3) 
Try not to use a childish "tone of voice." In everyday life I am a mature professional and despite my upcoming motherhood I would like to be approached that way. (28 years, nulli, Q1)

\section{Information Provision}

Women wanted clear information presented in an unbiased fashion. Information should not be self-conflicting or ambiguous. A number of women felt that their midwife was trying to impose her own opinion during discussions, for example, promoting home birth and breastfeeding. Most women who mentioned information leaflets indicated that they felt they received too many and that this was not always appreciated.

In my opinion, don't promote home birth too much. (36 years, mult, Q2)

Things could be less pushy on breastfeeding. If you have made an informed choice to bottle feed, it would be nice if you also get some more information about this, instead of just keeping receiving leaflets about breastfeeding. (32 years, nulli, Q1)

Anticipate the person in front of you. For example; trying to give me brochures and booklets won't work. It is better not to be supply-oriented, but to ask if someone needs information about..... (31 years, mult, Q2)

Finally, the timing of information provision was of interest. Women commented that, in their opinion, some information was provided too early or too late.

Do not start about breastfeeding at 15 weeks. I understand that it is an important issue, but I can't do anything with it yet. (36 years, nulli, Q1)

\section{Clinical Competence}

Negative experiences during their care triggered respondents, at all three time points, to identify skills and competence as an area for improvement. Examples of the experiences include harsh or painful examinations, forgotten actions, and incorrect or delayed actions. Women expected complete and correct knowledge and some women expected an active discussion and further probing about their pregnancy-related physical or psychological complaints. Some women raised concerns about the midwives' clinical judgment around timing of referral to another care provider - with women experiencing the referral that they felt was too late or (a very few others) too early.

Do the catheterization well at once instead of twice. (31 years, nulli, Q3)

One should have recognized that my son would be so big and childbirth should have been initiated earlier. (40 years, nulli, Q3)

Earlier referral to the obstetrician in the case of rising blood pressure. (28 years, nulli, Q3)

Don't refer to the hospital too early, but rely more on the instinct and body of the woman in labor. (28 years, mult, Q1))

\section{Service Characteristics}

The main theme "service characteristics" included comments concerning the content of care and the organization and coordination of care.

\section{Content and Quantity of Care}

\section{Additional or Adjusted Care}

The theme "content and quantity of care" includes comments about what in women's opinion is part of the midwifery care or should be added or adjusted. This theme 
Baas, C.I., Erwich, J., Wiegers, T.A., Cock, T.P. de, Hutton, E.K. Women's suggestions for improving midwifery care in The Netherlands. Birth: Issue in Perinatal Care: 2015, 42(4), 369-378

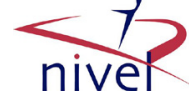

could also contain comments about the (personal preference of the) quantity of checkups or visits.

Personally, they don't have to visit me so often during the postpartum period. (24 years, mult, Q3)

Visit slightly more often during the postpartum period. (32 years, mult, Q3)

For improvement of the prenatal care, most suggestions were about additional care, such as more ultrasounds, more (screening) tests, including blood and urine tests, and more weight monitoring. Furthermore, a few women appreciated a proactive offer of a consultation 6 weeks postpartum by the midwife.

An ultrasound, every month, to have a better insight into the health of the baby. (38 years, nulli, Q3)

More blood and urine tests, more than 2 times.... (30 years, mult, Q3)

\section{Assistance and Support}

Most suggestions about the care during childbirth and postpartum were about assistance and support. Women expressed a need for more assistance and support at several stages of the process. During pregnancy, more attention should be given to their psychological well being and to the process of becoming a mother. Women wanted to talk about the upcoming birth more extensively. Also, the support in case of a miscarriage was regularly described as a possible area for improvement. During childbirth, an important aspect mentioned was the wish to be visited in the early onset of labor, after the women's first call. Women preferred the midwife not to leave her and her partner alone but to focus on her needs. In the postpartum period, women appreciate more support with breastfeeding. Many women expressed the need to see the care provider who had attended the birth soon after birth to talk about the childbirth and cope with the childbirth experience.

Besides technical medical attention, attention to the process of integration of being pregnant, giving birth and becoming a mother. (37 years, mult, Q2)

After a miscarriage, phone the client (back) to see how she is doing. (30 years, mult, Q1)

After the membranes are ruptured, remain in the house until the birth is over. Turn off cell phone at times when laboring woman has a hard time and needs help. Switch the phone to a colleague. (29 years, nulli, Q3)

After giving birth, in the first week postpartum, talk the childbirth experience over, this is what I have missed. And stay longer after childbirth. (28 years, mult, Q3)

\section{Information}

The comments in the questionnaires showed that there sometimes were shortcomings regarding individualized information provision. A rather large group of women would like to receive more information on a variety of topics, while others felt overwhelmed by all the information and suggested midwives should tailor the quantity of information to the women and their partners at each consultation. Explain the entire process, how many consults, attendance after birth. More explanation during the physical examination of my bump, blood pressure, and heartbeats of the baby. (33 years, nulli, Q2)

Give better information about physical complaints during pregnancy! You're so inexperienced during your first pregnancy. (24 years, mult, Q1) 
Baas, C.I., Erwich, J., Wiegers, T.A., Cock, T.P. de, Hutton, E.K. Women's suggestions for improving midwifery care in The Netherlands. Birth: Issue in Perinatal Care: 2015, 42(4), 369-378

Only provide information if it is requested, ask if you can offer information. (36 years, mult, Q1)

\section{Coordination of Care}

\section{Time Spent with the Client}

On average, women wanted the midwife to spend more time with them. In the prenatal and postnatal periods, women mentioned a lack of time during the visits: they also felt they did not always have the opportunity to ask their questions. Women indicated that they preferred the midwife to remain present for a longer period of time. Furthermore, some women suggested the midwife could improve her profession by not attending to more births at the same time, being on time at the birth, and providing more care directly after the birth (on call shifts of Dutch midwives are described in detail by Baas et al [34]).

Take more time for the check-ups, which are now so rushed that I only dare to ask the most necessary. Questions that have a lower priority, I search on the Internet. (36 years, mult, Q1)

I had the misfortune of 5 births during the weekend, so the midwife was a bit tired and in a hurry. That was unfortunate. (32 years, mult, Q3)

\section{Continuity of the Care Provider}

During the whole period of pregnancy, childbirth, and in the postpartum period, there was a strong demand for continuity of the care provider. A known midwife present during labor and birth is the most frequently mentioned aspect. For several women this means a preference for just one or two midwives. In the case of a larger number of midwives, they felt that they did not have the possibility to form a bond. However, some women suggested that perhaps they should meet all the midwives, to avoid having an unknown care provider during childbirth.

Keep seeing the same one or two midwives. Not so many different faces every time! (31 years, mult, Q2)

I have got the feeling that I have been sitting in front of too many different midwives, so you could not build a relationship with one of them, it feels like you are a number. (32 years, nulli, Q2)

\section{Continuity of Care}

At all three time points, women indicated that they did not appreciate discontinuity of care, for example, caregivers who did not know what was said at previous appointments so that women had to repeat their personal story. Better communication among the midwifery teams appears to be needed to make sure the different midwives use the same approach of care, and give information and advice in a consistent manner.

With several midwives you get different opinions, in my case, they are not the same. Because of this, as a future mother you get insecure and this is not necessary if everyone is aware. (31 years, nulli, Q2)

Women noted that interdisciplinary collaboration and referral could be improved. Some mentioned that information transfer could be better. After responsibility for the care was transferred to the obstetrician during pregnancy, women appreciated if their midwife stayed in touch. Others preferred the midwife to accompany her and her 
partner to the hospital and assist them during a referral (stay to talk to the hospital staff) or in case of transfer during labor, and to stay until the child is born.

Improve the communication with the hospital and agreeing on policies about the referral. (37 years, nulli, Q3)

During admission to the hospital with a medical reason, call in more often, instead of a single phonecall and instead of only seeing each other again after the birth. (33 years, mult, Q3)

\section{Accessibility and Waiting Time}

A topic that was mentioned very frequently was the long waiting times. Additionally, women suggested an increased accessibility of the practice by telephone. They would also appreciate more possibilities to visit the practice for prenatal consultations and ultrasounds. In general, accessibility of midwifery practices could be improved. Consultations are from 9:00 to 14:00, therefore I often had to take off from work. I would like extended times to make an appointment. (28 years, nulli, Q2)

Not every day an ultrasound is possible, which is unfortunate if you think you have had a miscarriage and then you have to wait another day for the answer. (29 years, mult, Q2)

\section{Involvement of Students}

Women often pointed out that the way that students are educated in practice can be improved. Women suggested that student midwives should not be given too much responsibility and must always work under the supervision of the midwife. In addition, having too many different students in the practice was highlighted as a problem by some women. Women preferred the midwife herself to ask the women for permission to have a student present and the midwife should divide her attention properly between the woman and the student.

In my opinion, they let a certain student loose to soon, when that wasn't appropriate yet. (22 years, mult, Q3)

Do not leave everything to trainees. Redo all the check-ups themselves, after the student has performed them, such as blood pressure etc. (32 years, mult, Q1)

\section{Administration, Accommodation, and Being Informed}

There were a few comments about the accommodation, such as a preference for a more homelike environment, privacy in the building, and availability of parking spaces. Administrative problems with the planning of the consultation were also indicated. Some of the women mentioned that they liked to be updated about the current state of affairs in the midwifery practice, such as changes in the organization of the practice and if there are new locums. Additionally, women indicated that if they cannot be seen at the scheduled time, they would appreciate it if this would be communicated to the people in the waiting room.

Sometimes they run over time enormously, maybe they could report this to their clients in the waiting room. (30 years, mult, Q3)

\section{DISCUSSION}

Our study explored women's experiences with their midwife and midwifery care and studied women's suggestions for improving midwifery care in the Netherlands. Our purpose was to involve women by adding their perspective to the discussion about 
the maternity care system in the Netherlands. The women's suggestions could be clustered around provider characteristics, including interpersonal skills, communication, and competence, and around service characteristics including content and coordination of care. In almost all themes, a desire emerged for "individualized care." Although in qualitative research, it is not as much about quantity as about quality, it was interesting that the majority of the comments were about interpersonal skills, information provision, and a lack of continuity of the care provider. Informed by the suggestions of the women, women and their families would be served by: a more personal, friendly approach with enough time spent per client, more information and information specifically tailored to the person, and more continuity of care provider during the prenatal, natal, and postnatal periods.

Although the Dutch maternity care system may be unique in some regard, the themes identified as shortcomings or points for improvement by women are likely to apply similarly in other jurisdictions [3, 6, 8, 9, 35-38].

Interpersonal skills, the importance of kindness, being taken seriously, and being listened to have been reported by women in many other countries and in other systems $[3,8,9,35-37,39]$. The lack of information and the lack of individually tailored information were some aspects that were discussed and researched in Sweden, Australia, and England [8, 37, 40]. Internationally there is less consensus with respect to the importance of continuity of the caregiver. While some studies described continuity of the caregiver as important and highly valued by women [9, $20,41,42,44-46]$, others concluded that the focus on continuity of the caregiver through pregnancy, childbirth, and postpartum may be misguided $[6,15,20,38,43]$. Our study found that women would appreciate more continuity of the caregiver, a finding that is consistent with earlier research findings from the Netherlands [20, 42]. All themes derived in our study were direct or indirect elements within personcentered care, or in the case of maternity care, women-centered care [47-49]. A more women-centered and individualized approach, which keeps clients informed and actively involved in their care, would likely increase women's satisfaction with the maternity care experience [36].

One model of maternity care, which has a focus on women-centered care is the midwifery-led continuity model. The philosophy behind the midwifery-led continuity model is normality, continuity of care, and being cared for by a known, trusted midwife during childbirth [18].

However, even in a context where some women receive midwife-led continuity care, there is still a desire for more individualized care. Ironically, the current developments in the Netherlands are not moving toward a more midwifery-led continuity of care model but toward an integrated/shared care model and more protocolized care [25]. More protocolized care potentially carries the risk of moving away from individualized care [50], which makes the case for it to be carefully assessed, the remodeling of the current system to assure that the voice of women is adequately heard and heeded. To make improvements in the existing maternity care system, some suggestions require greater adjustments to implement than others. For instance, really listening to pregnant women and their partners and treating them well does not necessarily require additional financial commitments. This could be an important way to start improving quality and satisfaction [36]. Perhaps more challenging is to spend more time with women who need it and provide women with individualized information. These aspects should be possible to arrange in the current 
Baas, C.I., Erwich, J., Wiegers, T.A., Cock, T.P. de, Hutton, E.K. Women's suggestions for improving midwifery care in The Netherlands. Birth: Issue in Perinatal Care: 2015, 42(4), 369-378

maternity care system, although this might have financial implications. More continuity of the care provider throughout the prenatal, intrapartum, and postnatal period will require more effort and probably will also require a decrease in the current caseload per midwife, which brings financial implications with it.

The open-ended questions, answered by a large number of women who started their care in primary care, provided extensive information on the experiences, opinions, and suggestions of women about their midwives and the maternity care system in the Netherlands. One of the disadvantages of the survey method we used is a limited length of responses and lack of opportunity for further clarification that can be gained by personal interview approaches. The advantage of this method was that we could sample a large number of women. The sample favored those who were motivated to answer the questions. Despite the stated limitations, the study provides valuable insight into the perceptions and views of women about the maternity care (organization) they experienced. We recommend that midwives and midwifery organizations explore mechanisms to enhance individualization of care to address some of the issues raised by women.

\section{ACKNOWLEDGMENTS}

We thank Dr. Trudy Klomp and Dr. Evelien Spelten, the initiators of the Deliver study.

\section{REFERENCES}

1Simkin P. The experience of maternity in a woman's life. J Obstet Gynecol Neonatal Nurs 1996;25(3):247-252.

2 Green JM. Integrating women's views into maternity care research and practice. Birth 2012;39(4):291-295.

3Hodnett ED. Pain and women's satisfaction with the experience of childbirth: A systematic review. Am J Obstet Gynecol 2002;186:160-172.

4Redshaw M. Women as consumers of maternity care: Measuring "satisfaction" or "dissatisfaction"? Birth 2008;35:73-76.

5 Goodman P, Mackey MC, Tavakoli AS. Factors related to childbirth satisfaction. J Adv Nurs 2004;46:212-221.

6 Green JM, Renfrew MJ, Curtis PA. Continuity of carer: What matter to women? A review of the evidence. Midwifery 2000;16:186-196.

7Larkin P, Begley CM, Devane D. Women's experiences of labour and birth: An evolutionary concept analysis. Midwifery 2009;25:49-59.

8 Hildingsson I, Haines $\mathrm{H}$, Cross $\mathrm{M}$, et al. Women's satisfaction with antenatal care: Comparing women in Sweden and Australia. Women and Birth 2012;26:e9-e14.

9Hildingsson I, Radestad I. Swedish women's satisfaction with medical and emotional aspects of antenatal care. J Adv Nurs 2005;52(3):239-249.

10 Hundley V, Ryan M. Are women's expectations and preferences for intrapartum care affected by the model on offer? BJOG 2004;111:550-560.

11 Gamble J, Creedy D, Teakle B. Women's expectations of maternity services: A community-based survey. Women and Birth 2007;20:115-120.

12 Van Teijlingen E, Hundley V, Rennie AM, et al. Maternity satisfaction studies and their limitations: "What is, must still be best." Birth 2003;30:75-82.

13Waldenstrom U, Rudman A. Satisfaction with maternity care: How to measure and what to do. Women's Health 2008;4:211-214.

14Davey M, Brown S, Bruinsma F. What is it about antenatal continuity of caregiver that matters to women? Birth 2005;32:262-271.

15Farquhar M, Camilleri-Ferrante C, Todd C. Continuity of care in maternity services:

Women's views of one team midwifery scheme. Midwifery 2000;16:35-47. 
Baas, C.I., Erwich, J., Wiegers, T.A., Cock, T.P. de, Hutton, E.K. Women's suggestions for improving midwifery care in The Netherlands. Birth: Issue in Perinatal Care: 2015, 42(4), 369-378

16 Hodnett ED. Continuity of caregivers for care during pregnancy and childbirth. Cochrane Database Syst Rev 2008;1:CD000062.

17Biro MA, Waldenstrom U, Brown S, Pannifex JH. Satisfaction with team midwifery care for low- and high-risk women: A randomized controlled trial. Birth 2000;30:1-10.

18 Sandall J, Soltani $\mathrm{H}$, Gates S, et al. Midwife-led continuity models versus other models of care for childbearing women. Cochrane Database Syst Rev 2013;8:CD004667.

19 Hatem M, Sandall J, Devane D, et al. Midwife-led versus other models of care for childbearing women. Cochrane Database Syst Rev 2008;8(4):CD004667.

20Wiegers TA. The quality of maternity care services as experienced by women in the Netherlands. BMC Pregnancy and Childbirth 2009;9:18.

21Fitzpartick R. Surveys of patient satisfaction: I-Important general considerations. BMJ 1991;302:887-889.

22Stichting Perinatale Registratie Nederland. Perinatale Zorg in Nederland 2013. Utrecht: Stichting Perinatale Registratie Nederland, 2014. Accessed April 20, 2015. Available at:

23College Perinatale Zorg. Netwerk goed geboren; samenwerken aan verbeteren van geboortes. Accessed April 20, 2015. Available at:

24Mohangoo AD, Buitendijk SE, Hukkelhoven CW, et al. Hoge perinatale sterfte in Nederland vergeleken met andere Europese landen: Peristat-11-studie Nederland. Tijdschrift voor Geneeskunde 2008;152(50):2718-2727.

25De Vries R, Nieuwenhuijze M, Buitendijk SE. What does it take to have a strong and dependent profession of midwifery? Lessons from the Netherlands. Midwifery 2013;29:1122-1128.

26 Stuurgroep zwangerschap en geboorte. Een goed begin, Veilige zorg rondom zwangerschap en geboorte. 2009.

27Fumagalli PF, Radaelli G, Lettieri E, et al. Patient empowerment and its neighbours: Clarifying the boundaries and their mutual relationships. Health Policy 2015;119:384-394.

28Menichetti J, Liberi C, Lozza E, Graffigna G. Giving patients a starring role in their own care: A bibliometric analysis of the on-going literature debate. Health Expect 2014; Nov 4. doi: 10.1111/hex.12299. [Epub ahead of print]

29Legare F, Stacey D, Turcotte s, et al. Interventions for improving the adoption of shared decision making by healthcare professionals (Review). Cochrane Database Syst Rev 2014;9:CD006732.

30Nilsen ES, Myrhaug HT, Johansen M, et al. Methods of consumer involvement in developing healthcare policy and research, clinical practice guidelines and patient information material (Review). Cochrane Database Syst Rev 2006;3:CD004563.

31Di Blasi Z, harkess E, Ernst E, et al. Influences of context effect on health outcomes: A systematic review. Lancet 2001;357:757-762.

32Stewart M, Brown JB, Donner A, et al. The impact of patient centered care on outcomes. J Fam Pract 2000;49(9):796-804.

33Mannien J, Klomp T, Wiegers T, Pereboom M, et al. Evaluation of primary care midwifery in the Netherlands: Design and rationale of a dynamic cohort study (DELIVER). BMC Health Serv Res 2012;12:69.

34Baas $\mathrm{C}$, Wiegers $\mathrm{T}$, de Cock $\mathrm{P}$, et al. Continuous support during childbirth by maternity care assistants: An exploration of opinions in the Netherlands. Inter J Child 2013;3:76-85.

35Jenkins MG, Ford JB, Morris JM, Roberts CL. Women's expectations and experiences of maternity care in NSW-What women highlight as most important. Women and Birth 2014;27(3):214-219.

36Hildingsson I, Thomas JE. Women's perspectives on maternity services in Sweden: Processes, problems and solutions. J Midwifery Womens Health 2007;52(2):126-133.

37Redshaw M. Institutional processes and individual responses: Women's experiences of care in relation to cesarean birth. Birth 2010;37(2):150-158.

38Spurgeon P, Hicks C, Barwell F. Antenatal, delivery and postnatal comparisons of maternal satisfaction with two pilot changing childbirth schemes compared with a traditional model of care. Midwifery 2001;17:123-132.

39Morgan M, Fenwick N, McKenzie C, Wolfe CDA. Quality of midwifery led care: Assessing the effects of different models of continuity for women's satisfaction. Quality in Health Care 1998;7:77-82. 
Baas, C.I., Erwich, J., Wiegers, T.A., Cock, T.P. de, Hutton, E.K. Women's suggestions for improving midwifery care in The Netherlands. Birth: Issue in Perinatal Care: 2015, 42(4), 369-378

40Thompsons R, Miller YD. Birth control: To what extent do women support being informed and involved in decisions about pregnancy and birth procedures? BMC Pregnancy Childbirth 2013;14:62.

41Tracy SK, Hartz DL, Tracy MB, et al. Caseload midwifery care versus standard maternity care for women of any risk: M@NGO, a randomized controlled trial. Lancet 2013;382:1723-1732.

42Fontein $Y$. The comparison of birth outcomes and birth experiences of low-risk women in different sized midwifery practices in the Netherlands. Women and Birth 2010;23:103-110.

43Waldenstrom U. Continuity of carer and satisfaction. Midwifery 1998;14:207-2013.

44Williams K, Lago L, Lainchbury A, et al. Mothers' view of caseload midwifery and the value of continuity of care at an Australian regional hospital. Midwifery 2010;26:615-621.

45Homer CSE, Davis GK, Cooke M, Barclay LM. Women's experiences of continuity of midwifery care in a randomized controlled trial in Australia. Midwifery 2002;18:102-112.

46Dahlberg $U$, Aune I. The woman's birth experience-The effect of interpersonal relationships and continuity of care. Midwifery 2013;29:407-415.

47Morgan S, Yoder LH. A concept analysis of person-centered care. J Holist Nurs 2012;30:6.

48Dwamena F, Holmes-Rovner M, Gaulden CM, et al. Interventions for providers to promote a patient-centered approach in clinical consultations (Review). Cochrane Database Syst Rev 2012;12:CD003267.

49Pope R, Graham L, Patel S. Women-centered care. Int J Nurs Stud 2001;38:227-238.

50 Amerling R, Winchester JF, Ronco C. Guidelines have done more harm than good. Blood Purif 2008;26(1):73-76. 
Baas, C.I., Erwich, J., Wiegers, T.A., Cock, T.P. de, Hutton, E.K. Women's suggestions for improving midwifery care in The Netherlands. Birth: Issue in Perinatal Care: 2015, 42(4), 369-378

\section{TABLES AND FIGURES}

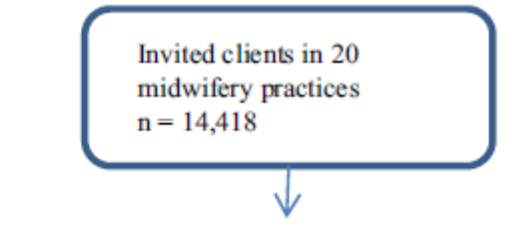

Women who participated by returning at least one of the questionnaires $\mathrm{n}=7,685$
Non-responders $(\mathrm{n}=6,733)$, information for 912 women regarding reasons for non-response: miscarriage $(25.9 \%)$, not interested $(15.8 \%)$, language problems $(11.7 \%)$

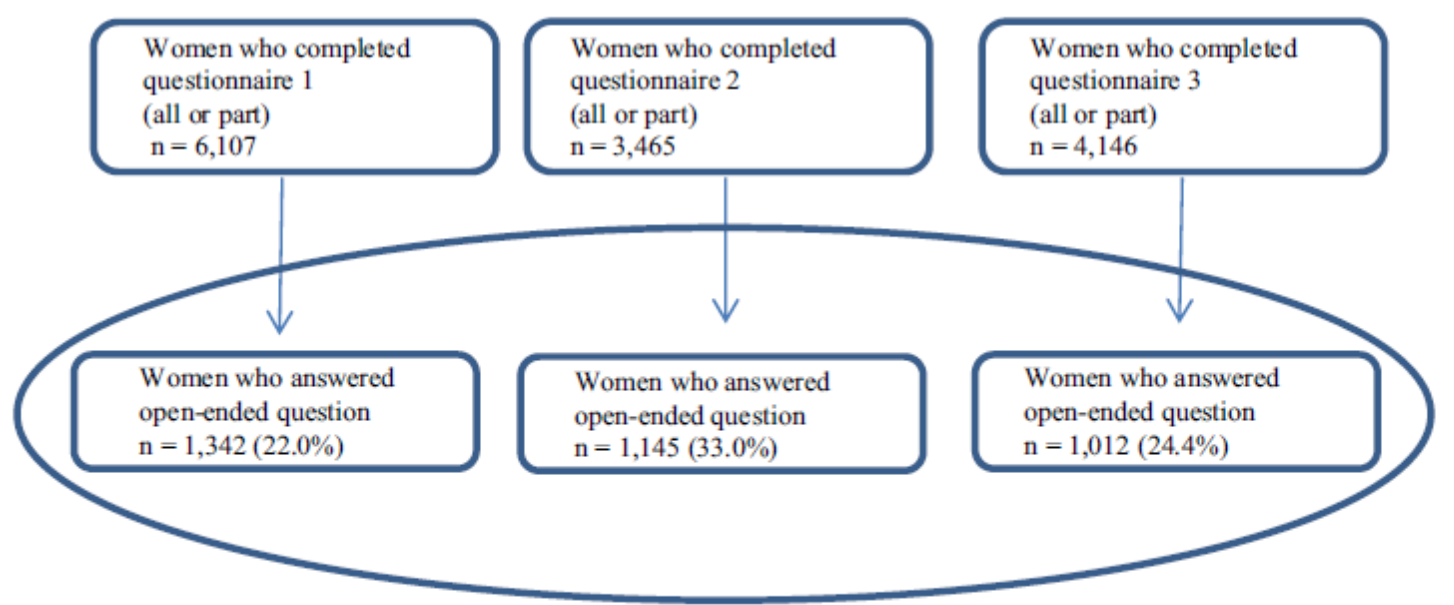

Fig. 1. Number of participants in the "DELIVER" study, who responded to the open-ended question: "Do you have any suggestions on how your midwife could improve his/her provision of care?" 
Baas, C.I., Erwich, J., Wiegers, T.A., Cock, T.P. de, Hutton, E.K. Women's suggestions for improving midwifery care in The Netherlands. Birth: Issue in Perinatal Care: 2015, 42(4), 369-378

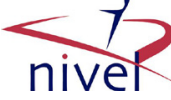

Table 1. Background Characteristics of the Women Who Responded to Questionnaire One, Two or Three (Q1, Q2, Q3) of the DELIVER Questionnaires, Organized by Women Who Did or Did Not Respond to the Open-Ended Question: "Do You Have Any Suggestions on How Your Midwife Could Improve His/Her Provision of Care?”

\begin{tabular}{|c|c|c|c|}
\hline & $\begin{array}{c}\text { Women who responded to the } \\
\text { open-ended question in } \\
Q 1, Q 2 \text {, or } Q 3 \\
(\mathrm{n}=2,594)\end{array}$ & $\begin{array}{c}\text { Women who did not respond } \\
\text { to the open-ended question } \\
\text { in } Q 1, Q 2, \text { or } Q 3 \\
(\mathrm{n}=5,093)\end{array}$ & $\begin{array}{c}\text { Overall survey sample; } \\
\text { women who responded } \\
\text { to } Q 1, Q 2, \text { or } Q 3 \\
(\mathrm{n}=7,685)\end{array}$ \\
\hline Maternal age (year) (mean) & 30.81 & 30.38 & 30.52 \\
\hline Missing & 3 & 5 & 8 \\
\hline \multicolumn{4}{|l|}{ Parity, n (\%) } \\
\hline Primi & $1,279(49.5 \%)$ & $2,338(46.0 \%)$ & $3,617(47.2 \%)$ \\
\hline Multi & $1,307(50.5 \%)$ & $2,740(54.0 \%)$ & $4,047(52.8 \%)$ \\
\hline Missing & 6 & 15 & 21 \\
\hline \multicolumn{4}{|l|}{ Nationality, n (\%) } \\
\hline Dutch & $2,445(94.5 \%)$ & $4,734(93.3 \%)$ & $7,179(93.7 \%)$ \\
\hline Non-Dutch: Western & $73(2.8 \%)$ & $139(2.7 \%)$ & $212(2.8 \%)$ \\
\hline Non-Dutch: Non-Western & $79(2.7 \%)$ & $199(3.9 \%)$ & $268(3.5 \%)$ \\
\hline Missing & 5 & 21 & 26 \\
\hline \multicolumn{4}{|l|}{ Education level, n (\%) } \\
\hline Low & $216(8.4 \%)$ & $957(18.9 \%)$ & $1,173(15.4 \%)$ \\
\hline Middle & $780(30.2 \%)$ & $1,995(39.4 \%)$ & $2,775(36.3 \%)$ \\
\hline High & $1,586(61.4 \%)$ & $2,107(41.7 \%)$ & $3,693(48.3 \%)$ \\
\hline Missing & 10 & 34 & 44 \\
\hline
\end{tabular}

Table 2. Themes and Subthemes, Created Using a Qualitative Thematic Content Analysis of the Responses to the "DELIVER" Open-Ended Question: "Do You Have Any Suggestions on How Your Midwife Could Improve His/Her Provision of Care?"

\begin{tabular}{llll}
\hline Overarching concept & \multicolumn{1}{c}{ Main themes } & \multicolumn{1}{c}{ Subthemes } & \multicolumn{1}{c}{ More detailed subthemes } \\
\hline Individualized care & Provider characteristics & Interpersonal skills & Interaction with client and others \\
& & Communication & Communications skills \\
& Information provision \\
& Service characteristics & Content and quantity of care & Additional or adjusted care \\
& & Assistance and support \\
& Coordination of care & Information \\
& & Time spent with client \\
& & Continuity of care provider \\
& & Continuity of care \\
& & Accessibility \\
& & Waiting time \\
& & Involvement of students \\
& & Administration/accommodation \\
& & Being informed \\
\hline
\end{tabular}

